\title{
Off-label uses of the Pipeline embolization device: a review of the literature
}

\author{
Purvee D. Patel, BA, ${ }^{1,2}$ Nohra Chalouhi, MD, ${ }^{1}$ Elias Atallah, MD, ${ }^{1}$ Stavropoula Tjoumakaris, MD, ${ }^{1}$ \\ David Hasan, MD, ${ }^{3}$ Hekmat Zarzour, MD, ${ }^{1}$ Robert Rosenwasser, MD, ${ }^{1}$ and Pascal Jabbour, MD ${ }^{1}$
}

1'Department of Neurosurgery, Thomas Jefferson University and Jefferson Hospital for Neuroscience, Philadelphia, Pennsylvania; ${ }^{2}$ Department of Neurological Surgery, Rutgers Robert Wood Johnson Medical School, Rutgers University, New Brunswick, New Jersey; and ${ }^{3}$ Department of Neurosurgery, University of lowa Carver College of Medicine, lowa City, lowa

\begin{abstract}
The Pipeline embolization device (PED) is the most widely used flow diverter in endovascular neurosurgery. In 2011, the device received FDA approval for the treatment of large and giant aneurysms in the internal carotid artery extending from the petrous to the superior hypophyseal segments. However, as popularity of the device grew and neurosurgeons gained more experience, its use has extended to several other indications. Some of these off-label uses include previously treated aneurysms, acutely ruptured aneurysms, small aneurysms, distal circulation aneurysms, posterior circulation aneurysms, fusiform aneurysms, dissecting aneurysms, pseudoaneurysms, and even carotid-cavernous fistulas. The authors present a literature review of the safety and efficacy of the PED in these off-label uses.
\end{abstract}

https://thejns.org/doi/abs/10.3171/2017.3.FOCUS1742

KEY WORDS Pipeline embolization device; off-label uses; aneurysms

$\mathrm{I}$ $\mathrm{N}$ recent years, the Pipeline embolization device (PED) has gained popularity as a treatment option for intracranial aneurysms. This flow diverter is an endoluminal, self-expanding, braided mesh tube made with 48 strands of platinum-tungsten and cobalt-chromium-nickel alloy wires. ${ }^{5,54}$ It works by diverting blood flow away from the aneurysm, leading to thrombosis of the aneurysm while also maintaining patency of the parent vessel. ${ }^{54}$ The device has proven to be a safe and effective therapy for large, giant, and complex intracranial aneurysms. ${ }^{38}$ In a comparative study of large unruptured saccular aneurysms, the PED provided higher aneurysm occlusion rates than coiling, with no additional morbidity and similar clinical outcomes. ${ }^{14}$ The authors of these studies concluded that the PED might be a preferred treatment option for this subtype of aneurysms.

As of 2011, the PED has gained FDA approval for use in adults with giant and large aneurysms that extend from the petrous to superior hypophyseal segments of the internal carotid artery (ICA). ${ }^{54}$ Although initially developed for that use, over time its off-label uses have expanded to include a variety of aneurysm types including previously treated aneurysms, ruptured aneurysms, posterior circula- tion aneurysms, small aneurysms, distal aneurysms, fusiform aneurysms, dissecting aneurysms, pseudoaneurysms, and carotid-cavernous fistulas (CCFs). This review article discusses some of those off-label uses and the results attained across institutions by using this device.

\section{Methods}

Articles eligible for our literature review were initially searched using PubMed with the term "Pipeline Embolization Device." After we developed a list of off-label uses from our initial search, we expanded it to include individual diagnoses, using search terms including "ruptured aneurysms," "small aneurysms," "distal circulation," "posterior circulation," "previously stented aneurysms," "previously coiled aneurysms," "fusiform aneurysms," "dissecting aneurysms," "pseudoaneurysms," and "carotid cavernous fistulas." All articles within these searches were screened, and we included articles focusing on the use, safety, and efficacy of the PED for these specific off-label uses. These articles included large prospective and retrospective reviews, smaller case series, and case reports. Table 1 summarizes the studies that were conducted over

ABBREVIATIONS ACA = anterior cerebral artery; $\mathrm{ACOA}=$ anterior communicating artery; $\mathrm{CCA}=$ cavernous carotid aneurysm; $\mathrm{CCF}=$ carotid-cavernous fistula; ICA = internal carotid artery; $\mathrm{MCA}=$ middle cerebral artery; $\mathrm{mRS}=$ modified Rankin Scale; PED = Pipeline embolization device; PRU = P2Y12 reaction unit; SAH = subarachnoid hemorrhage. 
TABLE 1. Reported studies on the safety and efficacy of the PED for its off-label uses

\begin{tabular}{|c|c|c|c|c|}
\hline Off-Label Use \& Study & $\begin{array}{c}\text { No. of } \\
\text { Aneurysms }\end{array}$ & $\begin{array}{l}\text { Complete Occlusion } \\
\text { Rate (no.) }{ }^{*}\end{array}$ & Complication Rate (no.)† & $\begin{array}{c}\text { Mortality } \\
\text { Rate (no.) } \dagger\end{array}$ \\
\hline \multicolumn{5}{|l|}{ Previously treated aneurysms } \\
\hline Chalouhi et al., $2014^{13}$ & 15 & $64.3 \%(9 / 14)$ & $6.7 \%(1) \ddagger ; 26.7 \%(4) \S$ & $0 \%(0)$ \\
\hline Daou et al., 2015 & 32 & $76.7 \%(23 / 30)$ & $3 \%(1) \ddagger$ & $0 \%(0)$ \\
\hline Daou et al., $2016^{23}$ & 21 & $55.6 \%$ & $14.3 \%(3)$ & NA \\
\hline Kühn et al., $2016^{41}$ & 24 & $66.7 \%(10 / 15)$ & $0 \%(0)$ & $0 \%(0)$ \\
\hline \multicolumn{5}{|l|}{ Ruptured aneurysms } \\
\hline Lin et al., $2015^{45}$ & 26 & $78.3 \%(18 / 23)$ & $19.2 \%(5) \Uparrow$ & $11.5 \%(3)$ \\
\hline Cruz et al., 2013 & 20 & $94 \%(15 / 16)$ & $15 \%(3)$ & $5 \%(1)$ \\
\hline McAuliffe et al., $2012^{50}$ & 11 & $88.9 \%(8 / 9)$ & $0 \%(0)$ & $18.2 \%(2)$ \\
\hline Chalouhi et al., $2015^{15}$ & 20 & $80 \%(12 / 15)$ & $5 \%(1) \uparrow$ & $5 \%(1)$ \\
\hline Chan et al., 2014 & 8 & $100 \%(8 / 8)$ & $25 \%(2)$ & $0 \%(0)$ \\
\hline \multicolumn{5}{|l|}{ Small aneurysms } \\
\hline Chalouhi et al., $2015^{16}$ & 100 & $72 \%(54 / 75)$ & $3 \%(3)$ & $0 \%(0)$ \\
\hline Chalouhi et al., $2014^{11}$ & 40 & $80 \%(31 / 39)$ & $5 \%(2)$ & $0 \%(0)$ \\
\hline Saatci et al., 2012 & 155 of 251 & $93.8 \%(136 / 145)$ & $1 \%(2) \ddagger^{* *} ; 13.1 \%(25) \S^{* *}$ & $0.5 \%(1)^{* *}$ \\
\hline Griessenauer et al., 2017 & 149 & $87 \%(107 / 123)$ & $\begin{array}{c}\text { Neurological } 15.4 \%(23) \text {; thromboembolic } 8.7 \%(13) ; \\
\text { procedural } 6 \%(9)\end{array}$ & $0 \%(0)$ \\
\hline Lin et al., 2013 & 44 & $66.7 \%(14 / 21)$ & $2.3 \%(1) \mp \rrbracket ; 6.8 \%(3) \S$ & $2.3 \%(1)$ \\
\hline \multicolumn{5}{|l|}{ Distal circulation aneurysms } \\
\hline Lin et al., 2016 & 28 & $77.8 \%(21 / 27)$ & Periprocedural 10.7\% (3); postprocedural 21.4\% (6) & $0 \%(0)$ \\
\hline Nossek et al., 2017 & 5 & $100 \%(5 / 5)$ & $0 \%(0)$ & $0 \%(0)$ \\
\hline Zanaty et al., 2014 & 10 & $77.8 \%(7 / 9)$ & $30 \%(3)$ & $0 \%(0)$ \\
\hline Puri et al., 2016 & 7 & $100 \%(6 / 6)$ & $0 \%(0)$ & $0 \%(0)$ \\
\hline Martínez-Galdámez et al., 2015 & 25 & $64 \%(14 / 22)$ & $4 \%(1) \ddagger ; 8 \%$ (2)§; intraprocedural $12 \%(3)$ & $0 \%(0)$ \\
\hline Dabus et al., 2017 & 20 & $69 \%(11 / 16)$ & $5 \%(1) \mp \rrbracket ; 5 \%(1) \S$ & $5 \%(1)$ \\
\hline Clarençon et al., 2017 & 8 & $71.4 \%(5 / 7)$ & $0 \%(0)$ & $0 \%(0)$ \\
\hline \multicolumn{5}{|l|}{ Posterior circulation aneurysms } \\
\hline Phillips et al., 2012 & 32 & $96 \%(22 / 23)$ & $\begin{array}{c}\text { Permanent neurological } 9.4 \%(3) \text {; infarction } 9.4 \%(3) ; \\
\text { hematoma } 6.3 \%(2)\end{array}$ & $0 \%(0)$ \\
\hline Munich et al., 2014 & 12 & $90 \%(9 / 10)$ & $25 \%(3) \rrbracket$ & $8.3 \%(1)$ \\
\hline Chalouhi et al., $2013^{12}$ & 7 & $50 \%(3 / 6)$ & $0 \%(0)$ & $0 \%(0)$ \\
\hline Albuquerque et al., 2015 & 17 & $78.6 \%(11 / 14)$ & $5.9 \%(1) \ddagger ; 23.5 \%(4)$ & $0 \%(0)$ \\
\hline Zumofen et al., 2015 & 6 & $100 \%(6 / 6)$ & $0 \%(0)$ & $0 \%(0)$ \\
\hline \multicolumn{5}{|l|}{ Fusiform \& dissecting aneurysms } \\
\hline Fischer et al., 2014 & 69 & $67 \%(33 / 49)$ & Clinical impairment $12 \%$ (8); morbidity $5 \%$ & $8 \%$ \\
\hline Monteith et al., 2014 & 24 & $31.8 \%(7 / 22)$ & $16.7 \%(4) \ddagger ; 4.2 \%(1) \S$ & $4.2 \%(1)$ \\
\hline de Barros Faria et al., 2011 & 23 & $69.5 \%(16 / 23)$ & $8.7 \%(2)$ & $0 \%(0)$ \\
\hline Brzezicki et al., 2016 & 13 & $75 \%(6 / 8)$ & $7.6 \%(1)$ & $0 \%(0)$ \\
\hline \multicolumn{5}{|l|}{ Pseudoaneurysms } \\
\hline Tsang et al., 2015 & 7 & $100 \%(5 / 5)$ & $\begin{array}{l}\text { Periprocedural infarction } 14.3 \%(1) \text {; delayed thrombosis } \\
42.9 \%(3)\end{array}$ & $0 \%(0)$ \\
\hline \multicolumn{5}{|l|}{ Mostly case reports } \\
\hline \multicolumn{5}{|l|}{ CCF } \\
\hline \multicolumn{5}{|l|}{ Mostly case reports } \\
\hline \multicolumn{5}{|c|}{$\begin{array}{l}\text { NA = not available. } \\
\text { * Complete }(100 \%) \text { occlusion rate at the late } \\
\dagger \text { These refer to procedure-related complica } \\
\text { † Major procedure-related complication that } \\
\S \text { Minor procedure-related complication that } \\
\text { I Includes deaths in the complication rate. } \\
\text { ** Rates from a larger set of aneurysms, bec }\end{array}$} \\
\hline
\end{tabular}


the years to assess the safety and efficacy of the PED in its off-label uses.

\section{Previously Treated Aneurysms}

Conventional therapies for intracranial aneurysms are microsurgical clipping and endovascular coiling. ${ }^{47}$ Two well-conducted, randomized, controlled trials have evaluated these 2 methods in the treatment of intracranial aneurysms and looked at recurrence and retreatment rates. ${ }^{7,66} \mathrm{In}$ the International Subarachnoid Hemorrhage Trial (ISAT), $9.0 \%$ of patients treated with coiling and $0.85 \%$ of patients treated with microsurgical clipping had to be retreated due to recurrence. ${ }^{7}$ In the Barrow Ruptured Aneurysm Trial (BRAT), the retreatment rates at the 3-year follow-up were $13 \%$ and $5 \%$ for coil-treated and clip-treated patients, respectively ${ }^{66}$ Similar recurrence and retreatment rates were described in later studies as well..$^{8,10,28}$ Given the not insignificant rate of recurrence associated with conventional treatments (coiling in particular), several investigators have studied the safety and efficacy of the PED as a treatment for recurrent aneurysms after previous coiling, stenting, or microsurgical clipping.

Chalouhi and colleagues presented one of the earlier studies that looked at the PED as treatment for recurrent aneurysms. ${ }^{8}$ Their series included 15 patients with recurrent aneurysms; 8 previously treated with coiling, 4 with stent insertion and coiling, 2 with telescoping stent, and 1 with surgical clipping. Of the patients available for follow-up, $64.3 \%$ had complete occlusion and $28.6 \%$ had near-complete occlusion. One patient (6.7\%) had a major complication and 4 (26.7\%) had minor complications. The authors believed that the morbidity rates associated with PED might be higher than those of more traditional methods. This same group later looked at subsets of patients with recurrent aneurysms that were previously coiled and previously stented. ${ }^{23,24}$ One study followed 32 patients with single lesions who had recurrence of previously coiled aneurysms, and investigators found a total rate of complete and near-complete occlusion of $86.7 \%$, a complication rate of $3 \%$, and no mortalities. ${ }^{24}$ In a series of 21 previously stented aneurysms, the complete occlusion rate after PED placement was found to be $55.6 \%$ and the complication rate was $14.3 \% .{ }^{23}$ In this second study, the authors compared these results with a group of patients who underwent PED placement for aneurysms not previously stented. They concluded that the PED was less effective in managing previously stented aneurysms compared with nonstented aneurysms, and can also be associated with a higher complication rate in the previously treated aneurysms.

Kühn et al. found promising results in their series of 24 patients who underwent PED placement for previously clipped and coiled aneurysms ${ }^{41}$ The complete or near complete occlusion rates of previously treated ruptured and unruptured aneurysms was $94.4 \%$ at 6 months and $93.3 \%$ at 12 months. These investigators also did not observe any severe procedure-related complications. A report of 2 patients with recurrent previously clipped aneurysms who underwent PED placement also presented good outcomes. ${ }^{28}$ This was one of the few reports that looked specifically at recurrent aneurysms that had previ- ously undergone microsurgical clipping. There is a need for larger studies to assess the safety and efficacy of the PED in treating such cases.

\section{Ruptured Aneurysms}

The PED has mostly been used to treat unruptured aneurysms, whereas its use for acutely ruptured aneurysms has been limited and is theoretically contraindicated, given the need for dual antiplatelet therapy. When treating aneurysmal subarachnoid hemorrhages (SAHs), multiple additional intracranial procedures may be required, such as external ventricular drain placement, ventriculoperitoneal shunt insertion, or decompressive craniotomy for hematoma evacuation. ${ }^{45}$ These subsequent surgeries can be complicated by the dual antiplatelet therapy that is required in conjunction with PED placement. In addition, placement of flow diverters like the PED results in gradual rather than immediate thrombosis of the aneurysm. Considering this and the antiplatelet therapy, the risk of rehemorrhage would be theoretically higher with the PED ${ }^{45}$ However, in certain cases of complex ruptured aneurysms, the PED may still serve as a good alternative (and sometimes may be the only available option) because these aneurysms are anatomically and technically more difficult to treat using standard techniques. ${ }^{45}$

A number of case series have assessed the outcomes of the PED for acutely ruptured aneurysms. Lin and colleagues presented the largest series on PED treatment for ruptured aneurysms, looking at a total of 26 cases ${ }^{45}$ The periprocedural complication rate was $19.2 \%(5 / 26)$ and included 3 deaths. Complete occlusion was achieved in $78.3 \%$, and a modified Rankin Scale (mRS) score of 0-2 was reported in $76.9 \%$. The authors of this study concluded that due to the high complication rate, this procedure should only be used for ruptured aneurysms that are too difficult to treat by other, more traditional means. Similar results were seen in other studies as well. A series of 20 patients with aneurysmal SAHs who underwent PED placement had a procedure-related complication rate of $15 \%$ and 1 procedure-related death. ${ }^{20}$ Aneurysm occlusion rates were $75 \%$ at the 6-month follow-up and $94 \%$ at the 12-month follow-up. A smaller series of 11 cases was presented by McAuliffe et al..$^{50}$ There were 2 deaths due to acute aneurysm rerupture and, of the remaining 9 patients, 8 had complete occlusion at the 6-month follow-up. There were no reported procedure-related symptomatic complications.

Chalouhi et al. presented a series of 20 patients undergoing PED placement for acutely ruptured aneurysms. ${ }^{15} \mathrm{~A}$ procedure-related complication was seen in only 1 patient, who experienced an acute aneurysm rerupture, leading to her death. The occlusion rate was $80 \%$, and $95 \%$ of patients had a favorable outcome (mRS score of 0-2) at most recent follow-up. Last, a small series of 8 ruptured dissecting aneurysms had 2 procedure-related symptomatic complications and complete obliteration of all 8 aneurysms at follow-up. ${ }^{17}$

Furthermore, certain anticoagulation protocols can be put into place to prevent the feared consequences associated with PED placement in ruptured aneurysms due to dual antiplatelet therapy. The standard management for 
the prevention of thromboembolic events when using flow diverters is pretreatment with aspirin and clopidogrel for 7-10 days prior to the procedure. ${ }^{9}$ When treating ruptured aneurysms with the PED in conjunction with this dual antiplatelet therapy, there is a concern for hemorrhagic complications. Chalouhi and colleagues described a new regimen for anticoagulation that was recently implemented in the hope of minimizing the risk of thromboembolic and hemorrhagic complications. ${ }^{9}$ The protocol entails starting a maintenance infusion of tirofiban, a glycoprotein IIb/ IIIa inhibitor, immediately after the PED is placed and discontinuing after 2 hours, and also administering a single dose of aspirin and clopidogrel intraoperatively with no pretreatment prior to the procedure. They assessed the safety and efficacy of this protocol in 46 patients being treated with the PED for aneurysms, and complications were found in 2 patients (4.3\%). Of the 2 complications, only 1 was hemorrhagic and did not lead to a permanent morbidity. From this experience it was concluded that such a protocol is safe and is a good alternative to the standard dual antiplatelet regimen, especially in patients being treated for ruptured aneurysms.

In sum, the PED may be particularly helpful in acutely ruptured aneurysms that are not amenable to coiling or clipping. It can also be used in a staged fashion 1 or 2 weeks after partial coiling of the aneurysm dome. It is generally preferable to place an external ventricular drain if treatment with the PED is contemplated.

\section{Small Aneurysms}

Although FDA approval for the PED is for giant and large aneurysms, many institutions have expanded the use of this device to include small aneurysms as well. The cutoff margin of what defines a small aneurysm differs among physicians, but was reported to be $<7-10 \mathrm{~mm}{ }^{11,16,35,44,64}$ Many studies have found favorable outcomes, suggesting that PED is a safe and efficacious treatment option for small aneurysms, similar to the results of PED use for large and giant aneurysms. ${ }^{16}$

Chalouhi and colleagues used the PED in the treatment of 100 patients with small aneurysms $(\leq 7 \mathrm{~mm}) .{ }^{16} \mathrm{In}$ their series, $85 \%$ of aneurysms were adequately (completely or nearly completely) occluded at the most recent follow-up, and the rate of procedure-related, symptomatic complications was as low as 3\%. They concluded that the PED was associated with low complication rates and high occlusion rates when used for the treatment of small aneurysms. In another study conducted by the same group, the results of the PED for 40 small aneurysms that were matched and compared with 160 small aneurysms treated with stent-assisted coiling were reported. ${ }^{11}$ The complication rate was 5\% in the PED cohort and 3\% in the stent-coil group. The PED group had a higher aneurysm occlusion rate $(80 \%)$ compared with the stent-coil group (70\%), but this did not reach statistical significance. The authors concluded that the 2 procedures had similar complication rates and clinical outcomes, making the PED a promising alternative option to consider.

In one of the larger series, 155 small aneurysms (of a total of 251) were treated with the PED ${ }^{64}$ In this study by Saatci et al., $93.8 \%$ of small aneurysms had total occlu- sion within 6 months of the procedure, and the overall permanent morbidity and mortality rates were $1 \%$ and $0.5 \%$, respectively. Griessenauer et al. presented their results in 149 small $(\leq 7 \mathrm{~mm})$ aneurysms, making theirs the largest series assessing the use of PED for small aneurysms specifically. ${ }^{35}$ The complete occlusion rate was $87 \%$ at most recent follow-up. The rate of thromboembolic and symptomatic procedural complications was $8.7 \%$ and $6 \%$, respectively, and there was a single death $(0.9 \%)$ that was not related to the PED placement. In another study looking at 44 small aneurysm cases, Lin et al. found adequate (complete or nearly complete) occlusion in $80 \%$ of small aneurysms within 6 months of treatments. ${ }^{44}$ One patient $(2.3 \%)$ experienced a major complication of early SAH that led to the death of that patient. Three patients $(6.8 \%)$ also experienced periprocedural complications, all of which were successfully managed and resolved without any additional complications. This study reported lower complication rates and a higher rate of early angiographic success when using the PED to treat small aneurysms compared with large and giant aneurysms. The favorable outcomes of all the studies presented here suggest that the PED is a safe and efficient therapy that should be considered for the treatment of small aneurysms. In our institution, the PED has become a first-line option for small and simple intracranial aneurysms.

\section{Distal Circulation Aneurysms}

Distal aneurysms arise from the middle cerebral artery (MCA) and anterior cerebral artery (ACA) distal to the anterior communicating artery (ACoA) complex. ${ }^{46,59}$ They account for $5 \%-10 \%$ of all intracranial aneurysms. ${ }^{59}$

There are theoretical contraindications to using PED for distal circulation aneurysms. The parent arteries of such aneurysms are small $(<2.5 \mathrm{~mm}$ in caliber), which makes PED placement technically more challenging. ${ }^{54}$ Complications related to PED placement in such small vessels include stenosis and parent artery occlusion secondary to neointimal hyperplasia, or an inflammatory response. ${ }^{30}$ However, because the process of hyperplasia and inflammation would be gradual, in-stent stenosis would also be expected to be gradual, allowing time for collateral vasculature formation. Distal aneurysms often arise at branch points, and so there is a risk of occluding a major branch. In addition, the $A_{1}$ segment of the ACA and the $M_{1}$ segment of the MCA, where many distal aneurysms arise, have a lot of lenticulostriate perforating vessels that can also be covered and occluded by PED placement, leading to strokes and secondary neurological deficits. ${ }^{46,54}$ In addition to the small caliber of the vessels associated with these aneurysms, there is also a more tortuous vasculature with more branches in the distal circulation, which poses another technical challenge. However, the more recent PEDs have been designed to be smaller and shorter, allowing for easier navigation and deployment of the device. ${ }^{30}$

For all of these above-mentioned factors, use of the PED for distal circulation aneurysms has been met with some reluctance in the neurosurgical field. However, it is being considered more often as an alternative, especially in cases of distal aneurysms that are deemed challenging to treat with the traditional treatment options. Further- 
more, the gold standard treatment for distal aneurysms, microsurgical clipping, although associated with high occlusion rates, also has an increased mortality and morbidity rate. ${ }^{59,69}$ Balloon- and stent-assisted coil embolization may require placement of multiple catheters into the parent vessel and therefore, when used in small parent vessels, may have an increased risk of thromboembolic complications. ${ }^{62}$ In such instances, a safer alternative in complicated cases can be of significant value.

A number of case reports and retrospective studies have assessed the safety and efficacy of PED use for distal circulation aneurysms. Lin et al. presented a retrospective review of 28 patients with distal aneurysms treated with PED. ${ }^{46}$ At an average follow-up of 7.7 months, $77.8 \%$ of patients were found to have complete aneurysm occlusion. The complication rate during the periprocedural period $(<$ 30 days) was $10.7 \%$, with no deaths. The majority of patients $(96.4 \%)$ had a good outcome, with mRS scores between 0 and 2, and 1 patient had a fair outcome, with an $\mathrm{mRS}$ score of 3. In a smaller series of 5 distal aneurysms presented by Nossek et al., all patients had complete occlusion between 5 and 14 months of device placement. ${ }^{59} \mathrm{In}$ this series the mean follow-up period was 21.25 months, and during that time none of the patients developed parent vessel occlusion or in-stent stenosis. Branch vessel patency was maintained in 4 of the 5 patients, with the fifth patient showing asymptomatic occlusion of the branch vessel with no clinical neurological deficits. Zanaty and colleagues reviewed 10 cases of MCA aneurysms treated with the PED. ${ }^{71}$ There was 1 periprocedural complication that improved after treatment, no deaths, and no technical complications in this series. The overall complication rate was $30 \%$ in this series, including periprocedural and long-term complications. Of the patients available for angiographic follow-up, $77.8 \%$ had complete occlusion of the aneurysm.

Puri and colleagues presented their experience treating 7 aneurysms distal to the circle of Willis. ${ }^{62}$ The complication rate was $0 \%$, and of the 6 patients who were available for angiographic follow-up, there was complete aneurysm occlusion in all patients. Martínez-Galdámez et al. also looked at the use of PED to treat 25 aneurysms beyond the circle of Willis. ${ }^{49}$ Their series had a complete occlusion rate of $64 \%$, and the remaining $36 \%$ had significantly reduced residual filling. When evaluating side branches that were covered by PED placement, $79 \%$ were found to be patent at follow-up. Six patients (27\%) had in-stent stenosis; however only 1 patient was symptomatic. There were 2 minor postoperative events that both resolved spontaneously within 24 hours, 1 major postoperative event, and no deaths, as well as 3 procedural complications that resolved without major deficits. In another series of 20 patients treated for complex ACA aneurysms with PED, the overall complete and near complete occlusion rates were $69 \%$ and $75 \%$, respectively. ${ }^{21}$ One patient experienced a major complication of a large intraparenchymal hemorrhage, which led to his death, and 1 patient had a small caudate infarct with complete recovery. Similar to the above-mentioned occlusion rates, Clarençon et al. demonstrated a 71.4\% complete occlusion rate in their series of distal ACA aneurysms treated with PED. ${ }^{19}$ There were no acute or delayed complications in this series.
Last, a few case reports also showed promising results. In 1 case, a fusiform aneurysm at the junction of $\mathrm{M}_{3}$ and $\mathrm{M}_{4}$ treated with PED resulted in complete aneurysm occlusion at the 3-month follow-up, a patent parent vessel, and no deficits in neurological function. ${ }^{30}$ Furthermore, PED was also used in a pediatric case of distal ACA aneurysm. Angiographic follow-up showed complete occlusion of the aneurysm and the patient had no postoperative neurological deficits. ${ }^{68}$ The promising outcomes of these studies support the use of the PED for treatment of aneurysms in the distal cerebrovascular circulation, especially in cases that are considered too difficult to treat using conventional methods.

\section{Posterior Circulation Aneurysms}

Numerous studies have demonstrated the safety and efficacy of the PED in the anterior circulation. ${ }^{18,48,51,56,64}$ However, the use of the PED in the posterior circulation is not as extensive due to the unique characteristics of the cerebral vasculature and aneurysms arising in this location. Specifically, numerous unforgiving perforator vessels arise in this area and supply brainstem structures; the occlusion of these perforators can lead to significant disabilities. ${ }^{53,60}$ Earlier studies looking into the use of the PED in the posterior circulation have demonstrated higher mortality and morbidity rates. ${ }^{60,65}$ Phillips and colleagues assessed the safety of PED placement in 32 patients with posterior circulation aneurysms. ${ }^{60}$ The aneurysm occlusion rate was $85 \%$ of patients with $>6$ months of followup and $96 \%$ of patients who were followed for $>1$ year. Of the 21 patients who had basilar artery aneurysms, perforator infarctions were seen in 3 patients (14\%), although just a single PED was used in each case. Phillips et al. concluded that clinical perforator infarction rates may be higher when the PED is placed within the basilar artery compared with the ICA.

More recent studies have demonstrated good outcomes with the device. Munich et al. assessed the outcomes in 12 patients with vertebrobasilar fusiform aneurysms treated with the PED..$^{53}$ The complete aneurysm occlusion rate was $90 \%$ in this study. Complications related to the procedure occurred in 3 patients, resulting in death in 1 of the cases and significant resolution in the other 2 cases. There were no thromboembolic complications seen in this series. The authors emphasized their strict adherence to adequate platelet inhibition to avoid such complications and also vigilant monitoring of patients receiving antiplatelet therapy to avoid hemorrhagic complications, and they were quite successful in their management. The need for longterm dual antiplatelet therapy in such cases was further supported by case reports that found delayed thrombosis after PED placement for large fusiform posterior circulation aneurysms in the cases in which antiplatelet therapy was altered or discontinued. ${ }^{32,40}$

Chalouhi and colleagues presented their series of 7 patients with posterior circulation aneurysms. ${ }^{12}$ They reported no procedural complications, perforating vessel infarcts, or new neurological deficits within the treated patients. Six patients were available for angiographic follow-up and of them, 3 had 100\% occlusion, 2 showed significant decrease in aneurysm size, and 1 experienced 
no change. In addition, the patency of perforator vessels was maintained in all cases. Another study treated 17 patients with posterior circulation aneurysms using the PED. ${ }^{1}$ The authors found complete or near-complete aneurysm occlusion in all the patients available for follow-up. A procedure-related complication leading to permanent disability was seen in only 1 patient. A study by Zumofen and colleagues assessed the safety and efficacy of PED in the treatment of 6 nonsaccular $\mathrm{P}_{1}$ or $\mathrm{P}_{2}$ segment aneurysms. ${ }^{72}$ All patients had aneurysm occlusion within 1 year, the majority within 6 months. There were no new permanent neurological symptoms or aneurysm recurrences noted in this series.

\section{Fusiform and Dissecting Aneurysms}

Fusiform aneurysms can occur in the setting of atherosclerotic disease and progress slowly over time, with involvement of the entire circumferential vessel wall. ${ }^{33}$ Dissecting aneurysms, on the other hand, often are a result of trauma or can occur spontaneously, and are caused by injury to and disruption of the internal elastic lamina. Due to their morphology, these types of aneurysms are considered challenging to treat using the standard surgical and endovascular methods. The PED may be a promising alternative for these otherwise challenging lesions that avoids parent vessel occlusion while sufficiently excluding the aneurysm.

Fischer et al. conducted one of the larger series, looking at 69 fusiform and dissecting aneurysms in 65 patients. ${ }^{33}$ At the latest follow-up, complete occlusion was seen in $67 \%$ of patients and reduced perfusion in $29 \%$. The morbidity rate was $5 \%$ and the mortality rate was $8 \%$. Monteith and colleagues reviewed 24 cases of fusiform aneurysms treated with the PED. ${ }^{52}$ They found the procedure-related minor morbidity and mortality rates to be $4.2 \%$ and $4.2 \%$, respectively, and found major complications in $16.7 \%$ of their patients. At their latest follow-up, 59\% of patients had $\geq 95 \%$ aneurysm occlusion. In their experience, the authors found the PED to be a safe and effective treatment for fusiform aneurysms with reasonable morbidity and mortality rates considering the complexity of these lesions.

A study conducted by de Barros Faria et al. followed 23 patients with dissecting aneurysms treated with the PED. ${ }^{25}$ Of the 16 patients who were available for at least 3 months of follow-up, $87.5 \%$ had complete occlusion. The overall occlusion rate of all patients, regardless of follow-up time, was $69.5 \%$. There were 2 procedure-related complications, both of which had complete resolution. In another study, 13 dissections presented in 11 patients, and of the 13 dissections, 11 were associated with pseudoaneurysms (discussed in further detail in the next section, Pseudoaneurysms). ${ }^{6}$ There was 1 nonsignificant procedure-related complication, and the complete occlusion rate at most recent follow-up was 75\%. Other small series and case reports also presented favorable outcomes when using PED therapy for the treatment of dissecting aneurysms. ${ }^{34,42,70}$

\section{Pseudoaneurysms}

Intracranial pseudoaneurysms can result from blunt or penetrating trauma, arterial dissection (as discussed in the previous section, Fusiform and Dissecting Aneurysms), infection, radiation, or following surgery. 2,3,37,67 Because they are not true aneurysms and are instead secondary to injury to the vessel wall, pseudoaneurysms lack a true, full-thickness wall and are contained only by a connective tissue layer. ${ }^{3}$ For this reason, they have an elevated risk of rupture, especially intraoperatively. However, endovascular interventions now allow for a less invasive means to treat these lesions. Traditionally, the treatment strategy has been parent artery sacrifice with or without revascularization, by open surgery or by endovascular means. ${ }^{2}$ Flow diverters such as the PED allow for exclusion of the pseudoaneurysm while still maintaining parent vessel patency.

One of the first cases using the PED for a traumatic intracranial pseudoaneurysm was presented by Amenta et al. ${ }^{3}$ Their patient developed a pseudoaneurysm following surgery that was treated with the PED. Within 4 months, there was complete obliteration of the pseudoaneurysm and successful endoluminal reconstruction of the damaged vessel. A few other case reports and small series also demonstrated successful use of the PED to treat pseudoaneurysms. ${ }^{2,29,39,57}$

The use of the PED is limited to pseudoaneurysms in which there is no active bleeding, because the efficacy of flow diverters depends on the lack of a significant pressure gradient across the pseudoaneurysm wall to promote thrombosis. ${ }^{2}$ Kadkhodayan and colleagues present a case further emphasizing this. ${ }^{37}$ Their patient initially presented with an actively bleeding pseudoaneurysm. The bleeding ceased spontaneously and a PED was placed shortly thereafter. However, just days later the patient presented again with rebleeding, and the vessel had to be sacrificed. The authors concluded that transient cessation of the bleeding is not sufficient to place PED for treatment. Use of the PED in cases of actively bleeding pseudoaneurysms would not be useful. Ischemic complications may also be associated with PED use. In a small series of 7 patients treated for postirradiated carotid pseudoaneurysms with the PED, 1 patient experienced multiple, periprocedural ischemic cerebral infarctions, and another 3 patients had delayed ICA thrombosis leading to a lacunar infarct in 1, whereas the other 2 remained asymptomatic. ${ }^{67}$ Although the PED was effective in excluding the pseudoaneurysms, the authors concluded that the high risk of ischemic complications did not support the use of flow diverters as a first-line treatment option.

The limited number of studies assessing the safety and efficacy of the PED for pseudoaneurysm treatment present mixed results. Although a few case reports and small series have shown promising results, much larger and more extensive studies would be needed to establish the role of the PED in treating pseudoaneurysms. Frequently, the PED is the only alternative to vessel sacrifice for pseudoaneurysms. We currently use the PED as a first-line option for pseudoaneurysms unless there is evidence of active bleeding, in which case parent vessel occlusion is used.

\section{Carotid-Cavernous Fistulas}

A CCF is an abnormal connection between the carotid artery and cavernous sinus that causes shunted blood to flow from the carotid artery into the cavernous sinus, either directly (arising directly from the carotid artery) or 
indirectly (arising from branches of the carotid artery). ${ }^{31}$ These lesions can occur spontaneously or as a result of trauma. Although the exact mechanism of formation is not known, there are many theories to explain the pathophysiology. The initial insult is injury to the vessels, which can be a direct tear from a bone fracture or the shear forces from trauma, rupture of a cavernous carotid aneurysm (CCA), or smaller breaks from chronic diseases such as arterial hypertension or atherosclerosis. ${ }^{31}$ The goal of treatment would be to occlude the CCF and restore normal flow through the ICA.

Unfortunately, only a handful of case reports demonstrate the use of the PED in treating CCFs. The earliest case was presented by Nadarajah et al., in which a young patient developed a posttraumatic, high-flow CCF that was then treated with the PED..$^{55}$ Follow-up angiograms confirmed successful treatment by showing no evidence of arteriovenous shunting. Pradeep et al. presented 2 additional cases of posttraumatic CCFs that were both adequately treated with the PED, leading to $\mathrm{CCF}$ occlusion and clinical improvement in both patients ${ }^{61}$ Favorable outcomes using the PED were also seen in a case of a direct high-flow CCF that resulted from the rupture of a CCA. ${ }^{58}$ A unique case was presented by Amuluru et al. Their patient had an unruptured CCA that was treated with PED placement. ${ }^{4}$ Postoperative angiograms revealed the formation of a direct CCF, which the physicians decided to treat with flow diversion, and the patient underwent a second PED procedure for the CCF. At the 12-month follow-up, angiograms showed complete resolution of the CCF and clinical improvement in the patient.

In the previously mentioned case report, $\mathrm{CCF}$ is presented as both a complication of PED placement in treatment of a CCA and also an off-label indication for the use of PED therapy. ${ }^{4}$ The CCF is a known complication of PED. In fact, a study by Roy et al. found a CCF rate of $11.4 \%$ in their series of 44 patients who underwent the PED procedure for CCA. ${ }^{63}$ Lin et al. presented 2 such cases of direct CCFs that formed as a result of delayed aneurysm rupture following PED treatment of CCA. ${ }^{43}$

In cases of posttraumatic and spontaneous $\mathrm{CCF}$, the PED may be a possible treatment option; however, there is a lack of larger studies to confirm the results of the few reported case reports and small series presented here. It should be mentioned that traditional methods such as transvenous and transarterial embolization have an excellent safety-efficacy profile and should continue to be offered as a first-line therapy for these patients.

\section{Potential Ways to Improve the Safety and Efficacy of PED Therapy}

When assessing the safety of the PED, some major complications to consider are hemorrhagic and thromboembolic events. At our institution, we have thoroughly explored the occurrence of these complications and taken measures to improve the overall safety and efficacy of this procedure. The monitoring of $\mathrm{P} 2 \mathrm{Y} 12$ receptor inhibition, in P2Y12 reaction units (PRUs), has been used to predict the incidence of hemorrhagic and thromboembolic complications, with the ideal preoperative range reported to be 60-240 PRUs. ${ }^{26,27}$ We reviewed 248 aneurysms in 231 patients treated with the PED at our institution to assess their PRU values and incidence of complications. ${ }^{22}$ Our results led us to believe that an optimal PRU range would be $70-150$, because values $<70$ were more likely to be associated with hemorrhagic complications and values $>150$ had greater chances of thromboembolic complications. Although these cutoff values had a high sensitivity (80\%), they had a low specificity (35\%). Therefore, treating neurosurgeons should be aware that patients with preoperative PRUs outside this range can still undergo the procedure without developing hemorrhagic or thromboembolic complications, and assess their candidacy on a case-by-case basis. Nonetheless, PRU is a vital factor to consider in the decision-making process.

Another factor to assess that can affect the safety and efficacy of the PED procedure is the number of PEDs deployed. Chalouhi et al. presented the first study comparing complication rates, aneurysm occlusion rates, and postoperative outcomes in 178 patients undergoing treatment for aneurysms using a single PED (126 patients) versus multiple PEDs (52 patients). ${ }^{13}$ They found that although both groups have similar aneurysm occlusion rates at their latest follow-ups, the patients in whom a single PED was placed had a significantly lower complication rate and better overall clinical outcomes. Based on these results, using a single PED may be sufficient in adequately treating the aneurysm, while maintaining a low incidence of complications. In fact, at our institution, almost all aneurysms are now treated with a single PED. ${ }^{36}$

Last, as physicians gain more experience with the PED procedure, the safety and efficacy is expected to increase as well. We previously presented the learning curve at our institution. ${ }^{36} \mathrm{We}$ assessed 120 aneurysms in 109 patients treated with the PED for intracranial aneurysms, divided into 3 consecutive, equal groups. The average procedure time significantly decreased from Group 1 to Group 3. The number of PEDs used also significantly decreased over time. The complication rates seen in the 3 groups $(16.2 \%, 8.3 \%$, and $5.6 \%$, respectively) followed a downward trend, with a dramatic and significant decrease in the rate of major complications; from $10.8 \%$ in the first group to $0 \%$ in Groups 2 and 3. Results supported presence of a definite learning curve, proving that physician experience performing the procedure is a significant factor determining the overall safety of the technique. Extensive formal training on the PED procedure may be implemented for neurosurgeons to further enhance the safety and efficacy profile of this technique. ${ }^{36}$

\section{Conclusions}

The PED has been studied and used extensively for its FDA-approved indications of large and giant aneurysms of the ICA. In the last few years, it has gained popularity in a number of off-label neurovascular uses. It has proven to be a safe and efficacious treatment option for many of these off-label uses, whereas others may still require larger, more extensive studies to draw conclusions. Nevertheless, the PED is a promising treatment alternative and should be considered by neurosurgeons for the treatment of complex neurovascular pathologies that may be deemed difficult 
to treat by using conventional surgical and endovascular techniques.

\section{References}

1. Albuquerque FC, Park MS, Abla AA, Crowley RW, Ducruet AF, McDougall CG: A reappraisal of the Pipeline embolization device for the treatment of posterior circulation aneurysms. J Neurointerv Surg 7:641-645, 2015

2. Ambekar S, Sharma M, Smith D, Cuellar H: Successful treatment of iatrogenic vertebral pseudoaneurysm using pipeline embolization device. Case Rep Vasc Med 2014:341748, 2014

3. Amenta PS, Starke RM, Jabbour PM, Tjoumakaris SI, Gonzalez LF, Rosenwasser RH, et al: Successful treatment of a traumatic carotid pseudoaneurysm with the Pipeline stent: case report and review of the literature. Surg Neurol Int 3:160, 2012

4. Amuluru K, Al-Mufti F, Gandhi CD, Prestigiacomo CJ, Singh IP: Direct carotid-cavernous fistula: a complication of, and treatment with, flow diversion. Interv Neuroradiol 22:569-576, 2016

5. Brouillard AM, Sun X, Siddiqui AH, Lin N: The use of flow diversion for the treatment of intracranial aneurysms: expansion of indications. Cureus 8:e472, 2016

6. Brzezicki G, Rivet DJ, Reavey-Cantwell J: Pipeline embolization device for treatment of high cervical and skull base carotid artery dissections: clinical case series. J Neurointerv Surg 8:722-728, 2016

7. Campi A, Ramzi N, Molyneux AJ, Summers PE, Kerr RS, Sneade M, et al: Retreatment of ruptured cerebral aneurysms in patients randomized by coiling or clipping in the International Subarachnoid Aneurysm Trial (ISAT). Stroke 38:1538-1544, 2007

8. Chalouhi N, Chitale R, Starke RM, Jabbour P, Tjoumakaris S, Dumont AS, et al: Treatment of recurrent intracranial aneurysms with the Pipeline embolization device. J Neurointerv Surg 6:19-23, 2014

9. Chalouhi N, Jabbour P, Daou B, Starke RM, Shields B, Hasan DM: A new protocol for anticoagulation with tirofiban during flow diversion. Neurosurgery 78:670-674, 2016

10. Chalouhi N, Jabbour P, Singhal S, Drueding R, Starke RM, Dalyai RT, et al: Stent-assisted coiling of intracranial aneurysms: predictors of complications, recanalization, and outcome in 508 cases. Stroke 44:1348-1353, 2013

11. Chalouhi N, Starke RM, Yang S, Bovenzi CD, Tjoumakaris $\mathrm{S}$, Hasan D, et al: Extending the indications of flow diversion to small, unruptured, saccular aneurysms of the anterior circulation. Stroke 45:54-58, 2014

12. Chalouhi N, Tjoumakaris S, Dumont AS, Gonzalez LF, Randazzo C, Starke RM, et al: Treatment of posterior circulation aneurysms with the Pipeline embolization device. Neurosurgery 72:883-889, 2013

13. Chalouhi N, Tjoumakaris S, Phillips JL, Starke RM, Hasan $\mathrm{D}, \mathrm{Wu} \mathrm{C}$, et al: A single Pipeline embolization device is sufficient for treatment of intracranial aneurysms. AJNR Am J Neuroradiol 35:1562-1566, 2014

14. Chalouhi N, Tjoumakaris S, Starke RM, Gonzalez LF, Randazzo C, Hasan D, et al: Comparison of flow diversion and coiling in large unruptured intracranial saccular aneurysms. Stroke 44:2150-2154, 2013

15. Chalouhi N, Zanaty M, Whiting A, Tjoumakaris S, Hasan D, Ajiboye N, et al: Treatment of ruptured intracranial aneurysms with the Pipeline embolization device. Neurosurgery 76:165-172, 2015

16. Chalouhi N, Zanaty M, Whiting A, Yang S, Tjoumakaris S, Hasan D, et al: Safety and efficacy of the Pipeline embolization device in 100 small intracranial aneurysms. J Neurosurg 122:1498-1502, 2015

17. Chan RS, Mak CH, Wong AK, Chan KY, Leung KM: Use of the Pipeline embolization device to treat recently ruptured dissecting cerebral aneurysms. Interv Neuroradiol 20:436441, 2014

18. Chitale R, Gonzalez LF, Randazzo C, Dumont AS, Tjoumakaris S, Rosenwasser R, et al: Single center experience with Pipeline stent: feasibility, technique, and complications. Neurosurgery 71:679-691, 2012

19. Clarençon F, Di Maria F, Gabrieli J, Shotar E, Zeghal C, Nouet A, et al: Flow diverter stents for the treatment of anterior cerebral artery aneurysms: safety and effectiveness. Clin Neuroradiol 27:51-56, 2017

20. Cruz JP, O'Kelly C, Kelly M, Wong JH, Alshaya W, Martin A, et al: Pipeline embolization device in aneurysmal subarachnoid hemorrhage. AJNR Am J Neuroradiol 34:271276, 2013

21. Dabus G, Grossberg JA, Cawley CM, Dion JE, Puri AS, Wakhloo AK, et al: Treatment of complex anterior cerebral artery aneurysms with Pipeline flow diversion: mid-term results. J Neurointerv Surg 9:147-151, 2017

22. Daou B, Starke RM, Chalouhi N, Barros G, Tjoumakaris S, Rosenwasser RH, et al: P2Y12 reaction units: effect on hemorrhagic and thromboembolic complications in patients with cerebral aneurysms treated with the Pipeline embolization device. Neurosurgery 78:27-33, 2016

23. Daou B, Starke RM, Chalouhi N, Tjoumakaris S, Hasan D, Khoury J, et al: Pipeline embolization device in the treatment of recurrent previously stented cerebral aneurysms. AJNR Am J Neuroradiol 37:849-855, 2016

24. Daou B, Starke RM, Chalouhi N, Tjoumakaris S, Khoury J, Hasan D, et al: The use of the Pipeline embolization device in the management of recurrent previously coiled cerebral aneurysms. Neurosurgery 77:692-697, 2015

25. de Barros Faria M, Castro RN, Lundquist J, Scrivano E, Ceratto R, Ferrario A, et al: The role of the Pipeline embolization device for the treatment of dissecting intracranial aneurysms. AJNR Am J Neuroradiol 32:2192-2195, 2011

26. Delgado Almandoz JE, Crandall BM, Scholz JM, Fease JL, Anderson RE, Kadkhodayan Y, et al: Last-recorded P2Y12 reaction units value is strongly associated with thromboembolic and hemorrhagic complications occurring up to 6 months after treatment in patients with cerebral aneurysms treated with the Pipeline embolization device. AJNR Am J Neuroradiol 35:128-135, 2014

27. Delgado Almandoz JE, Crandall BM, Scholz JM, Fease JL, Anderson RE, Kadkhodayan Y, et al: Pre-procedure P2Y12 reaction units value predicts perioperative thromboembolic and hemorrhagic complications in patients with cerebral aneurysms treated with the Pipeline embolization device. J Neurointerv Surg 5 (Suppl 3):iii3-iii10, 2013

28. Ding D, Starke RM, Evans AJ, Jensen ME, Liu KC: Endovascular treatment of recurrent intracranial aneurysms following previous microsurgical clipping with the Pipeline embolization device. J Clin Neurosci 21:1241-1244, 2014

29. Dolati P, Eichberg DG, Thomas A, Ogilvy CS: Application of Pipeline embolization device for iatrogenic pseudoaneurysms of the extracranial vertebral artery: a case report and systematic review of the literature. Cureus 7:e356, 2015

30. Durst CR, Hixson HR, Schmitt P, Gingras JM, Crowley RW: Endovascular treatment of a fusiform aneurysm at the M3M4 junction of the middle cerebral artery using the Pipeline embolization device. World Neurosurg 86:511.e1-511.e4, 2016

31. Ellis JA, Goldstein H, Connolly ES Jr, Meyers PM: Carotidcavernous fistulas. Neurosurg Focus 32(5):E9, 2012

32. Fiorella D, Hsu D, Woo HH, Tarr RW, Nelson PK: Very late thrombosis of a Pipeline embolization device construct: case report. Neurosurgery 67 (3 Suppl Operative):onsE313onsE314, 2010

33. Fischer S, Perez MA, Kurre W, Albes G, Bäzner H, Henkes 
H: Pipeline embolization device for the treatment of intraand extracranial fusiform and dissecting aneurysms: initial experience and long-term follow-up. Neurosurgery 75:364374, 2014

34. Gong D, Yan B, Dowling R, Mitchell P: Successful treatment of growing basilar artery dissecting aneurysm by Pipeline flow diversion embolization device. J Stroke Cerebrovasc Dis 23:1713-1716, 2014

35. Griessenauer CJ, Ogilvy CS, Foreman PM, Chua MH, Harrigan MR, He L, et al: Pipeline embolization device for small intracranial aneurysms: evaluation of safety and efficacy in a multicenter cohort. Neurosurgery 80:579-587, 2017

36. Jabbour P, Chalouhi N, Tjoumakaris S, Gonzalez LF, Dumont AS, Randazzo C, et al: The Pipeline embolization device: learning curve and predictors of complications and aneurysm obliteration. Neurosurgery 73:113-120, 2013

37. Kadkhodayan Y, Shetty VS, Blackburn SL, Reynolds MR, Cross DT III, Moran CJ: Pipeline embolization device and subsequent vessel sacrifice for treatment of a bleeding carotid pseudoaneurysm at the skull base: a case report. J Neurointerv Surg 5:e31, 2013

38. Kallmes DF, Brinjikji W, Cekirge S, Fiorella D, Hanel RA, Jabbour P, et al: Safety and efficacy of the Pipeline embolization device for treatment of intracranial aneurysms: a pooled analysis of 3 large studies. J Neurosurg [epub ahead of print October 28, 2016. DOI: 10.3171/2016.8.JNS16467]

39. Kerolus M, Tan LA, Chen M: Treatment of a giant vertebral artery pseudoaneurysm secondary to gunshot wound to the neck using Pipeline embolization device. Br J Neurosurg [epub ahead of print], 2016

40. Klisch J, Turk A, Turner R, Woo HH, Fiorella D: Very late thrombosis of flow-diverting constructs after the treatment of large fusiform posterior circulation aneurysms. AJNR Am J Neuroradiol 32:627-632, 2011

41. Kühn AL, de Macedo Rodrigues K, Lozano JD, Rex DE, Massari F, Tamura T, et al: Use of the Pipeline embolization device for recurrent and residual cerebral aneurysms: a safety and efficacy analysis with short-term follow-up. J Neurointerv Surg [epub ahead of print], 2016

42. Kühn AL, Kan P, Massari F, Lozano JD, Hou SY, Howk M, et al: Endovascular reconstruction of unruptured intradural vertebral artery dissecting aneurysms with the Pipeline embolization device. J Neurointerv Surg 8:1048-1051, 2016

43. Lin LM, Colby GP, Jiang B, Pero G, Boccardi E, Coon AL: Transvenous approach for the treatment of direct carotid cavernous fistula following Pipeline embolization of cavernous carotid aneurysm: a report of two cases and review of the literature. J Neurointerv Surg 7:e30, 2015

44. Lin LM, Colby GP, Kim JE, Huang J, Tamargo RJ, Coon AL: Immediate and follow-up results for 44 consecutive cases of small $(<10 \mathrm{~mm})$ internal carotid artery aneurysms treated with the Pipeline embolization device. Surg Neurol Int 4:114, 2013

45. Lin N, Brouillard AM, Keigher KM, Lopes DK, Binning MJ, Liebman KM, et al: Utilization of Pipeline embolization device for treatment of ruptured intracranial aneurysms: US multicenter experience. J Neurointerv Surg 7:808-815, 2015

46. Lin N, Lanzino G, Lopes DK, Arthur AS, Ogilvy CS, Ecker $\mathrm{RD}$, et al: Treatment of distal anterior circulation aneurysms with the Pipeline embolization device: a US multicenter experience. Neurosurgery 79:14-22, 2016

47. Liu A, Huang J: Treatment of intracranial aneurysms: clipping versus coiling. Curr Cardiol Rep 17:628, 2015

48. Lylyk P, Miranda C, Ceratto R, Ferrario A, Scrivano E, Luna $\mathrm{HR}$, et al: Curative endovascular reconstruction of cerebral aneurysms with the Pipeline embolization device: the Buenos Aires experience. Neurosurgery 64:632-643, N6, 2009

49. Martínez-Galdámez M, Romance A, Vega P, Vega A,
Caniego JL, Paul L, et al: Pipeline endovascular device for the treatment of intracranial aneurysms at the level of the circle of Willis and beyond: multicenter experience. J Neurointerv Surg 7:816-823, 2015

50. McAuliffe W, Wenderoth JD: Immediate and midterm results following treatment of recently ruptured intracranial aneurysms with the Pipeline embolization device. AJNR Am J Neuroradiol 33:487-493, 2012

51. McAuliffe W, Wycoco V, Rice H, Phatouros C, Singh TJ, Wenderoth $\mathrm{J}$ : Immediate and midterm results following treatment of unruptured intracranial aneurysms with the Pipeline embolization device. AJNR Am J Neuroradiol 33:164-170, 2012

52. Monteith SJ, Tsimpas A, Dumont AS, Tjoumakaris S, Gonzalez LF, Rosenwasser RH, et al: Endovascular treatment of fusiform cerebral aneurysms with the Pipeline embolization device. J Neurosurg 120:945-954, 2014

53. Munich SA, Tan LA, Keigher KM, Chen M, Moftakhar R, Lopes DK: The Pipeline embolization device for the treatment of posterior circulation fusiform aneurysms: lessons learned at a single institution. J Neurosurg 121:1077-1084, 2014

54. Murthy SB, Shah J, Mangat HS, Stieg P: Treatment of intracranial aneurysms with Pipeline embolization device: newer applications and technical advances. Curr Treat Options Neurol 18:16, 2016

55. Nadarajah M, Power M, Barry B, Wenderoth J: Treatment of a traumatic carotid-cavernous fistula by the sole use of a flow diverting stent. J Neurointerv Surg 4:e1, 2012

56. Nelson PK, Lylyk P, Szikora I, Wetzel SG, Wanke I, Fiorella D: The Pipeline embolization device for the intracranial treatment of aneurysms trial. AJNR Am J Neuroradiol 32:34-40, 2011

57. Nerva JD, Morton RP, Levitt MR, Osbun JW, Ferreira MJ, Ghodke BV, et al: Pipeline embolization device as primary treatment for blister aneurysms and iatrogenic pseudoaneurysms of the internal carotid artery. J Neurointerv Surg 7:210-216, 2015

58. Nossek E, Zumofen D, Nelson E, Raz E, Potts MB, Desousa $\mathrm{KG}$, et al: Use of Pipeline embolization devices for treatment of a direct carotid-cavernous fistula. Acta Neurochir (Wien) 157:1125-1130, 2015

59. Nossek E, Zumofen DW, Setton A, Potts MB, Raz E, Shapiro $\mathrm{M}$, et al: Treatment of distal anterior cerebral artery aneurysms with the Pipeline embolization device. J Clin Neurosci 35:133-138, 2017

60. Phillips TJ, Wenderoth JD, Phatouros CC, Rice H, Singh TP, Devilliers L, et al: Safety of the Pipeline embolization device in treatment of posterior circulation aneurysms. AJNR Am J Neuroradiol 33:1225-1231, 2012

61. Pradeep N, Nottingham R, Kam A, Gandhi D, Razack N: Treatment of post-traumatic carotid-cavernous fistulas using Pipeline embolization device assistance. J Neurointerv Surg 8:e40, 2016

62. Puri AS, Massari F, Asai T, Marosfoi M, Kan P, Hou SY, et al: Safety, efficacy, and short-term follow-up of the use of Pipeline embolization device in small $(<2.5 \mathrm{~mm})$ cerebral vessels for aneurysm treatment: single institution experience. Neuroradiology 58:267-275, 2016

63. Roy AK, Grossberg JA, Osbun JW, Skukalek SL, Howard BM, Ahmad FU, et al: Carotid cavernous fistula after Pipeline placement: a single-center experience and review of the literature. J Neurointerv Surg 9:152-158, 2017

64. Saatci I, Yavuz K, Ozer C, Geyik S, Cekirge HS: Treatment of intracranial aneurysms using the Pipeline flow-diverter embolization device: a single-center experience with longterm follow-up results. AJNR Am J Neuroradiol 33:14361446,2012

65. Siddiqui AH, Abla AA, Kan P, Dumont TM, Jahshan S, Britz 
GW, et al: Panacea or problem: flow diverters in the treatment of symptomatic large or giant fusiform vertebrobasilar aneurysms. J Neurosurg 116:1258-1266, 2012

66. Spetzler RF, McDougall CG, Albuquerque FC, Zabramski JM, Hills NK, Partovi S, et al: The Barrow Ruptured Aneurysm Trial: 3-year results. J Neurosurg 119:146-157, 2013

67. Tsang AC, Leung KM, Lee R, Lui WM, Leung GK: Primary endovascular treatment of post-irradiated carotid pseudoaneurysm at the skull base with the Pipeline embolization device. J Neurointerv Surg 7:603-607, 2015

68. Vachhani JA, Nickele CM, Elijovich L, Klimo P, Arthur AS: Flow diversion for treatment of growing A2 aneurysm in a child: case report and review of flow diversion for intracranial aneurysms in pediatric patients. World Neurosurg 96:607.e13-607.e17, 2016

69. Vora N, Thomas AJ, Gupta R, Gologorsky Y, Panapitiya N, Jovin T, et al: Endovascular treatment of distal anterior cerebral artery aneurysms: technical results and review of the literature. J Neuroimaging 20:70-73, 2010

70. Yeung TW, Lai V, Lau HY, Poon WL, Tan CB, Wong YC: Long-term outcome of endovascular reconstruction with the Pipeline embolization device in the management of unruptured dissecting aneurysms of the intracranial vertebral artery. J Neurosurg 116:882-887, 2012

71. Zanaty M, Chalouhi N, Tjoumakaris SI, Gonzalez LF, Rosen- wasser R, Jabbour P: Flow diversion for complex middle cerebral artery aneurysms. Neuroradiology 56:381-387, 2014

72. Zumofen DW, Shapiro M, Becske T, Raz E, Potts MB, Riina $\mathrm{HA}$, et al: Endoluminal reconstruction for nonsaccular aneurysms of the proximal posterior cerebral artery with the Pipeline embolization device. AJNR Am J Neuroradiol 36:1299-1302, 2015

\section{Disclosures}

Drs. Jabbour and Tjoumakaris are consultants for Medtronic.

\section{Author Contributions}

Conception and design: Jabbour, Patel, Chalouhi, Atallah. Acquisition of data: Patel, Chalouhi, Atallah. Analysis and interpretation of data: Patel, Chalouhi, Atallah. Drafting the article: Patel, Chalouhi. Critically revising the article: Jabbour, Patel, Chalouhi. Reviewed submitted version of manuscript: all authors. Approved the final version of the manuscript on behalf of all authors: Jabbour. Study supervision: Jabbour.

\section{Correspondence}

Pascal Jabbour, Department of Neurological Surgery, Thomas Jefferson University Hospital, 901 Walnut St., 3rd Fl., Philadelphia, PA 19107.email: pascal.jabbour@jefferson.edu. 